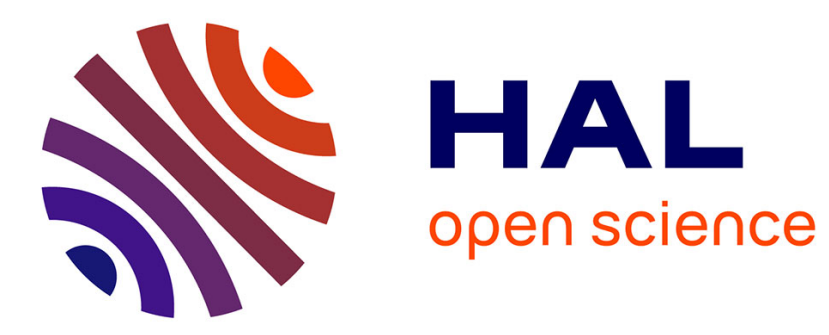

\title{
Modeling the heating and cooling energy demand of urban buildings at city scale
}

Loïc Frayssinet, Lucie Merlier, Frédéric Kuznik, Jean-Luc Hubert, Maya Milliez, Jean-Jacques Roux

\section{- To cite this version:}

Loïc Frayssinet, Lucie Merlier, Frédéric Kuznik, Jean-Luc Hubert, Maya Milliez, et al.. Modeling the heating and cooling energy demand of urban buildings at city scale. Renewable and Sustainable Energy Reviews, 2018, 81, Part 2, pp.2318-2327. 10.1016/j.rser.2017.06.040 . hal-01842364

\section{HAL Id: hal-01842364 https://hal.science/hal-01842364}

Submitted on 18 Jul 2018

HAL is a multi-disciplinary open access archive for the deposit and dissemination of scientific research documents, whether they are published or not. The documents may come from teaching and research institutions in France or abroad, or from public or private research centers.
L'archive ouverte pluridisciplinaire HAL, est destinée au dépôt et à la diffusion de documents scientifiques de niveau recherche, publiés ou non, émanant des établissements d'enseignement et de recherche français ou étrangers, des laboratoires publics ou privés. 


\title{
Modeling the heating and cooling energy demand of urban buildings at city scale
}

\author{
Loïc Frayssinet ${ }^{\mathrm{a}, \mathrm{b}}$, Lucie Merlier ${ }^{\mathrm{a}, \mathrm{b}}$, Frédéric Kuznik ${ }^{\mathrm{a}, \mathrm{b}}$, Jean-Luc Hubert ${ }^{\mathrm{a}, \mathrm{c}}$, \\ Maya Milliez $^{\mathrm{a}, \mathrm{c}}$, Jean-Jacques Roux ${ }^{\mathrm{a}, \mathrm{b}}$ \\ ${ }^{a}$ BHEE, CETHIL-EDF joint laboratory \\ ${ }^{b}$ Univ Lyon, CNRS, INSA-Lyon, Université Claude Bernard Lyon 1, \\ CETHIL, UMR5008, F-69621, Villeurbanne, France \\ ${ }^{c}$ EdF R\&D - Enerbat department \\ Avenue des Renardières - Ecuelles, F-77818, Moret sur Loing, France
}

\begin{abstract}
Many computational approaches exist to estimate heating and cooling energy demand of buildings at city scale, but few existing models can explicitly consider every buildings of an urban area, and even less can address hourly -or less- energy demand. However, both aspects are critical for urban energy supply designers. Therefore, this paper gives an overview of city energy simulation models from the point of view of short energy dynamics, and reviews the related modeling techniques, which generally involve detailed approaches. Analysis highlights computational costs of such simulations as key issue to overcome towards reliable microsimulation of the power demand of urban areas. Relevant physical and mathematical simplifications as well as efficient numerical and computational techniques based on uncertainties analysis and error quantification should thus be implemented.
\end{abstract}

Keywords: Heating and cooling in buildings, Power demand prediction,

Email address: loic.frayssinet@insa-lyon.fr (Loïc Frayssinet) 
District, City.

\section{Contents}

1 Introduction 3

1.1 General context . . . . . . . . . . . . . . . . . 3

1.2 Scope .......................... 4

1.3 Modeling issues . . . . . . . . . . . . . . . . 5

1.4 Objective ...................... 7

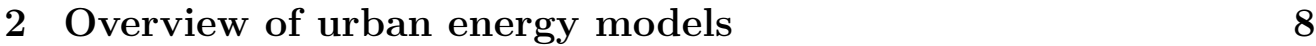

2.1 Top-down and bottom-up approaches . . . . . . . . . . . 8

2.2 Toward micro-simulation . . . . . . . . . . . . . . . . . 10

2.2.1 Building energy simulation . . . . . . . . . . . . . 11

2.2.2 Urban building energy simulation . . . . . . . . . 13

2.2.3 City energy simulation . . . . . . . . . . . . 15

2.3 Summary and discussion . . . . . . . . . . . . . . . . 17

3 Overview of sub-models used in building and urban energy $\begin{array}{ll}\text { simulations } & 19\end{array}$

3.1 Radiations models ... . . . . . . . . . . . . . . 20

3.1.1 Solar radiations . . . . . . . . . . . . . . 20

3.1 .2 Longwave radiations . . . . . . . . . . . . . . . . 21

3.1.3 Summary and discussion . . . . . . . . . . . . 22

3.2 Urban climate models . . . . . . . . . . . . . . . . . 23

3.2 .1 Urban canopy models . . . . . . . . . . . . . . . . 23

3.2.2 Microclimatic models . . . . . . . . . . . . . . . 24 
3.2.3 Measured and generated weather data . . . . . . . 25

3.2.4 Summary and discussion . . . . . . . . . . . 25

3.3 Envelope models . . . . . . . . . . . . . . . . . 27

3.3.1 Resistance-Capacitance analogy method . . . . . . . 27

3.3.2 Spatially-analytical method . . . . . . . . . . . 28

3.3.3 Response factors method . . . . . . . . . . . 28

3.3.4 Reduction methods . . . . . . . . . . . . . . . 29

3.3.5 Summary and discussion . . . . . . . . . . 30

4 Conclusions and outlooks $\quad 31$

5 Acknowledgments $\quad 32$

\section{Introduction}

\subsection{General context}

The study of urban energy consumption is becoming more and more important because of three main facts:

(1) Urban population is increasing: in 1950, 30\% of the world population lived in cities, and $54 \%$ in 2014, and this ratio will reach $66 \%$ in 2050 , that being around 6.5 billion of persons, i.e. 2.6 billion persons more than nowadays [1]. Therefore, urban development is a crucial issue, in particular from an energy point of view as urban energy consumption per capita is also increasing $(+32 \%$ in the last 40 years [2]).

(2) The energy paradigm changes: the need of dramatically reducing greenhouse gas emissions as well as fossil energy issues favor the use of renewable energies, which are often decentralized and intermittent. Related 
polices currently ongoing in many countries worldwide [3] change the previous centralized energy management scheme, which requires a better understanding and forecasting of power demand and power production, in particular in cities, where the network in dense.

(3) Urban heat stress during hot seasons due to the urban heat island (UHI) effect may further intensify effects of probable more frequent heat waves in the context of climate change [4]. This can lead to dramatic public health problems as well as energy issues due to the multiplication of active cooling devices, which would also contribute to increase urban air temperatures [5].

Therefore, urban energy consumption have been a critical research problem for the last 30 years years (Keirstead et al. [6] referenced 219 papers concerning only urban energy models), and will certainly still remains a major issue for the following years.

\subsection{Scope}

This paper focuses on the building sector, which is responsible of the main part of the global energy consumption (40\% of total final energy in the European Union [7]), and in particular on space conditioning (heating and cooling), which currently represents about $75 \%$ of the energy consumed by European residential buildings in 2014 [8]. The building sector is identified to have a "great potential" to improve energy efficiency [7] and to reduce greenhouse gas emission, thanks to refurbishment, including insulation and replacement of low-efficient energy technologies.

Moreover, renewable energy may relevantly be produced and used in buildings (e.g. solar panel and combined heat and power). But such a change 
implies to focus on power demand because of district network balance management problems (storage, sharing, etc.), and no more only on long term consumption.

Hence, this paper addresses building energy modeling at city scale, as integrated tools are needed for urban energy suppliers to manage energy networks and for city decision-makers to plan strategies in a context of urban growth and energy transition (point (2) of Sec. 1.1).

\subsection{Modeling issues}

The energy demand represents the energy used by energy systems, considering their efficiency and their behavior, to provide the energy needs. The energy consumption refers to the assessment (the sum) of the energy demand over a period, assuming that the energy demanded was supplied, whereas the power demand represents the instantaneous energy demand. Hourly energy demand is commonly used in building energy simulations (BESs) as the minimal temporal resolution required to estimate the power demand.

Simulating urban building power demand is more complex at the city scale than at building scale, mainly because of three reasons:

- A huge amount of information about built structures (geometry, physical properties of components, etc.) is needed because of the large size of the domain studied, whereas they are often unknown and difficult to obtain accurately $[6,9]$. Their determination needs expensive and time-consuming surveys and measurements;

- The behavior of the occupants (direct actions and use of systems) has a major impact on building energy demand [10-13] while at the distrit 
scale or lager, the temporal variability of occupants' behaviors makes the maximal total power demand different from the sum of the individual maximal power demands. This diversity requires specific models themselves based on extensive surveys [14];

- Because of the urban environment, buildings cannot be assumed standingalone as it is usually supposed in building energy models (BEMs). Effects of the urban environment on building energy needs have to be accounted for [15-22], while external loads, such as meteorological loads, cannot be estimated generically as they are particular for each building.

More precisely regarding this last point, meteorological loads of urban buildings and subsequently their energy behavior depend on (see Figure 1):

- Obstructions caused by surrounding constructions, which decrease the sky view factor, and consequently reduce solar gains (increase of the heating needs in winter and decrease of the cooling needs in summer) and the radiative cooling to the sky (reverse effect on the space conditioning needs) [15-19, 21, 23];

- Surrounding surfaces, which reflect solar radiations and emit and reflect longwave radiations, impact on the surface energy balance of urban buildings (e.g. a north-oriented surface may receive solar radiations from a south-facing opposite surface, therefore its thermal losses may be reduced) [17, 19];

- Urban morphology, which modifies airflows around buildings, and, consequently, impacts convective heat exchanges $[18,20,21]$ and the po- 
tential of natural ventilation of urban buildings, including infiltration [24];

- The general UHI effect, which means that air temperature within a city is often higher than in rural areas (decrease of the heating needs but increase of the cooling one [15, 20, 25-28]). According to Oke [29], the UHI results from the combination of the above mentioned phenomena, which generally increase urban surfaces temperatures, in addition to the high thermal absorbance of urban materials, the lack of vegetation (evaporative cooling), and the anthropogenic heat sources.

\subsection{Objective}

The aim of this paper is not to give an exhaustive review of studies addressing the simulation of building energy demand at the urban scale, but to identify the approaches and the models developed in the literature in order to simulate building heating and cooling power demand, from the building scale to the urban scale, taking into account the urban environment and possible changes in building characteristics. For this purpose, the paper is structured as follows: a first part (Sec. 2) presents the main approaches and methodologies used to estimate urban building energy consumption and particularly power demand at district or city scale; then a second part (Sec. 3) details the specific models used in these approaches in order to tackle modeling issues in the urban context; finally, the last part (Sec. 4) closes the paper and specifies outlooks. 


\section{Overview of urban energy models}

At the city scale, numerous phenomena of various scales interact, urban geometry is very complex and heterogeneous, and materials are diverse. Therefore, explicit simulation of urban energy demand requires huge amount of data, which are difficult to gather, and high computational capacities, which are currently not available for usual use $[6,9]$. Consequently, simplified approaches have been mostly developed.

\subsection{Top-down and bottom-up approaches}

Two approaches addressing urban energy issues were commonly defined: top-down and bottom-up. According to the review of Swan and Ugursal [30] about modeling techniques of energy consumption in the residential sector:

"Top-down models utilize the estimate of total residential sector energy consumption and other pertinent variables to attribute the energy consumption to characteristics of the entire housing sector. In contrast, bottom-up models calculate the energy consumption of individual or groups of houses and then extrapolate these results to represent the region or nation."

In other words, top-down models study city as an entity, according to its general characteristics. As the components of the city are not considered explicitly, top-down approaches are not able to consider explicitly the energy demand of each individual urban building. The total urban energy consumption is related to macroeconomic parameters, such as energy price and income, and to other parameters related to the city, such as population 
density and urban morphology. They are generally designed to give information for policy-makers, for whom monthly or annual energy consumption and aggregate information are sufficient. On the other hand, bottom-up models reconstitute the behavior of a city from the behaviors of its components, i.e. the buildings. Therefore, the urban energy demand is calculated as the sum of the energy demand of each building.

Bottom-up approaches enable each end-use consumption and the consumption of each building to be distinguished using statistical and engineering methods [30]. Statistical methods rely on huge amounts of various data originating from field measurements, energy supplier recordings, government publications or surveys, for instance. These historical data are used in regression analysis to establish relations between energy consumption and other parameters related to the building considered. In contrast, engineering methods calculate the energy demand of each energy system of buildings, using engineering-based models. These methods require an important collection of data about the physical properties of buildings components and characteristics of systems.

Hence, only engineering methods are able to simulate the consequences of important changes, as technology break, massive refurbishment or change of occupant behaviors, thanks to their high level of detail and their physical models, on the contrary to statistical approach based on historical data [14, 30, 31]. However, deterministic approaches used in engineering models are not able to properly consider diversity [14, 30, 32] and statistical models are necessary to relevantly include occupants' behaviors. Statistical tools can also simplify the determination of the huge amount of inputs of engineering 
models [31] (as for buildings stock dataset [32]).

\subsection{Toward micro-simulation}

In contrast to top-down and large scale bottom-up models, which consider aggregated and averaged quantities due to their large spatial and temporal resolutions, it is necessary to explicitly simulate each building of a city in order to accurately account for the distribution of the power demand at urban scale. This category of simulation (and, by extension the tool and the model associated) is called micro-simulation [9]. The micro scale refers to the building scale, and by extension, the meso scale to the district scale and the macro scale to the city scale. According to the classification of Swan and Ugursal [30], this type of model belongs to "sample engineering bottom-up models", but with the sample size equal to the domain size of the study (also called "urban building energy models" by Reinhart et al. [33]). Therefore, such models could be called full detailed sample engineering models, because each building belonging to the domain is explicitly considered. As the microsimulation exhaustively considers each building of the city, it is the strictest bottom-up approach.

Micro-simulation is needed by energy system and energy supply network designers, in order to simulate the power demand of each individual building within a district and for "spatially localized decision support" [9].

Nonetheless, most of micro-simulation models were validated with annual or monthly aggregated energy consumption measurements. Such a validation may be insufficient when models are further applied to assess power demand of individual urban buildings. As individual power demand of urban buildings depends on the diversity of occupant behaviors, rapid micro- 
meteorological phenomena and specific building characteristics, specific validation should be performed albeit it is made difficult by privacy issues and the lack of suited validation data.

Hence, to identify modeling approaches suited for urban power microsimulation, this part reviews existing approaches used to explicitly simulate urban building energy demand.

\subsubsection{Building energy simulation}

BES estimates heat transfers in the different building's elements and predict the behavior of energy systems, in order to provide detailed building energy assessment. The scales of the BESs are the followings: the micro-scale refers to components of the buildings (systems, elements of facade, etc.) and the macro-scale to the building (see Figure 2). BEMs can be also used to characterize archetype buildings of engineering-based bottom-up approaches $[31,34,35]$. In these cases, BEMs are solely used because it is unnecessary to precisely consider the local urban effects.

Towards urban micro-climate, the use of BES programs may be extended to evaluate effects of urban environments on building energy behavior. In particular, [25-27, 36, 37] performed BESs parameterized with local measured or generated weather data (see Sec. 3.2.3) for a generic building. The aim was to convert an increase of temperature due to an UHI into a variation of space conditioning energy consumption, considering building thermal behavior, rather than considering real urban building with its specific urban environment. Extending this approach, BEMs were coupled with an urban canopy model (see Sec. 3.2.1) in order to study the interactions between urban building energy demand and the urban climate [28, 38-40]. In this ap- 
proach, BESs are neither run for a specific building, but for a representative one, in order to determine its general impacts on the urban climate and the feedback on its energy needs.

More specific studies were also recently carried out. Especially, Ref. [17, 19] respectively used EnergyPlus [41] and ApacheCalc coupled with Daysim in order to determine the lighting electrical and space conditioning demands of a test room depending on the shading and reflection of solar radiation induced by different surrounding built structures (building heights, street widths, orientation, etc.).

Accounting for more physical phenomena and using the BES tool EnergyPlus, Yang et al. [21] evaluated the effects of urban environments on building energy needs by modifying the BEM boundary conditions and modeling of external solications based on microclimatic simulations performed using ENVI-met [42]. With this coupling, effects of urban environments in terms of short and long wave radiative heat transfers and local air temperature on building energy behavior were estimated. Also, Allegrini et al. [20, 43] used the BES tool TRNSYS [44] to simulate a street canyon in order to analyze the impact of its aspect ratio and its orientation on building energy needs considering both radiative and airflow-induced effects. More precisely, the street canyon was modeled as a large open atrium so that the indoor radiation model using Gebhart factors can apply to evaluate outdoor reflections of short and long wave radiations effects, and CFD-based specific external convective heat transfer coefficients were used to evaluate convective heat losses.

Hence, although BEMs are able to model the behavior of building com- 
ponents and are thus the bases of explicit urban power modeling, usual BES are not suited to perform district or urban scale simulations. As BEMs are originally designed for stand-alone buildings, they need improvements or couplings to integrate urban effects on urban building energy demand. According to the above-mentioned examples, BES were mainly used to simulate the energy demand of one, often theoretical, building in an urban context in order to identify general trends, not to study a real case. Surrounding buildings are often only assumed as obstructions, without explicit modeling of their thermal behaviors. As BESs tools are not designed to simulate numerous buildings while considering accurately the interactions between each others, performing BES at urban scale would require an important computational effort because of the consecutive calculations and the coupling processes [45]. This is all the more true if building interactions through microclimate is explicitly simulated using computational fluid dynamics (CFD) simulations.

\subsubsection{Urban building energy simulation}

Noticing that BES are originally designed for a stand-alone building, some tools were developed in order to model the interactions between urban structures and urban climatic conditions as well as building energy behavior. These tools are often thermo-radiative tools initially designed for urban lighting or pedestrian comfort studies, which were improved in order to evaluate building energy needs. They sometimes also include microclimate models. In the present paper, this category of combined models is called urban building energy model (UBEM) and the simulation associated urban building energy simulation (UBES). 
For example, He et al. [16] designed a "simulation tool for predicting the effect of outdoor thermal environment on building thermal performance in an urban block". They modeled geometrically the urban block and defined a uniform Cartesian mesh grid with a spatial resolution of $0.2 \mathrm{~m}$ for exterior surfaces, and split indoor volumes into thermal zones (one per story). Thermo-physical properties were attributed to each cell of the grid. Then the program solved heat balance equations for each cell every 15 minutes, giving the surface temperature of each cell, the indoor temperature and the power demand of the zones of a specific building. This simulation was based on a tool initially designed to predict outdoor thermal comfort [46] and improved to predict building energy needs.

Similarly, Bouyer et al. [18] added a building energy model to the thermoradiative model SOLENE and coupled it with the CFD program Fluent [47], in order to simulate the hourly energy needs of a building located in an urban block. SOLENE was first designed to model precisely solar luminance distribution within an urban area, and was then improved to compute thermo-radiative transfers and radiation-energy budgets [48], based on surface finite-elements of around 1 meter square. SOLENE was further coupled with Code_Saturne [49] to form the software suite SOLENE-microclimat $[50,51]$.

To recapitulate, UBEMs are improved urban thermo-radiative models able to predict building energy needs. They can be coupled with a CFD program in order to account for local wind and air temperature. They rely on a relatively fine temporal and spatial resolution for the accuracy of the thermo-radiative model. This particularity makes the simulation computa- 
tionally expensive. as the duration of the calculation substantially increases with the number of cells $[46,52]$. Therefore, their adaptation to simulate the energy behavior of numerous buildings would require substantial computational capacities (or time) or simplifications, especially when a CFD coupling is implemented (the simulation lasts 164 hours in Ref. [18] for two weeks).

\subsubsection{City energy simulation}

In order to overcome inherent limitations of BEM and UBEM for the calculation of the energy demand of numerous urban buildings, specific city energy models (CEMs) were developed. For instance, the platform called CitySim [53], the successor of SUNtool [54], was specifically designed for urban problems, to help urban decisions in a perspective of sustainable development, focusing on urban energy uses and various resource flows: energy, waste, water, etc. Compared to UBEMs, CitySim relies on a specific simplified radiation model $[55,56]$ and involves lower spatial resolution. It is therefore possible to explicitly simulate whole neighborhoods or districts to predict individually the energy demand of buildings over a year, as done in Ref. [57], where a neighborhood of 100 buildings is simulated. With this approach, urban surface temperatures are thus not finely determined, but the model mainly focuses on energy demand.

Other CES recently developed, or under development, are briefly recap in the Table 1. All of them can be used for city energy micro-simulation, but focus on different aspects (grid management, energy production, urban environment assessment, etc.).

Some adapted UBES performed on large urban areas and providing information about the energy demand of several buildings may be also included 
into CESs. In particular, Kawai et al. [22] used the same UBEM as He et al. [16] (see Sec. 2.2.1) for simulating the energy demand of a neighborhood but only for some days. Also, Gros et al. $[58,59]$ coupled SOLENE with a zonal-empirical microclimate model based on QUIC-URB [60], for airflows, coupled with zonal energy balance model [61], for external air thermal behavior. The resulting CES tool called EnviBatE, aims thus to assess the energy demand of neighborhoods taking into account microclimatic conditions while substantially reducing computational costs compared to e.g. SOLENE microclimat. In Ref. [58], a six months calculation of a neighborhood lasts 48 hours. Hence, the extension of UBES to CES is made possible using simplifications of the building energy and / or environmental model, by reducing the simulated period or model resolution or by increasing computational capacities.

Alternatively, several tools and platforms have been developed in order to calculate the energy demand of each building of a city directly from Geographical Information System (GIS), as in the Energy Atlas Berlin initiative [62], in EIFER works [63], with the SimStadt platform [64, 65], in the EnerCity project [66] and in the Li et al.'s methodology [67]. ${ }^{1}$ These approaches, called GIS-based simulations in Figure 3, can be considered as the successors of the Ratti et al.'s approach which estimated the building energy demand by analyzing digital elevation models [69]. Energy demand is roughly estimated based on geometrical data extracted from the GIS and building characteris-

\footnotetext{
${ }^{1}$ The majority of the models use the CityGML format (http://www.citygml.org/) for more interoperability and standardization. Furthermore, an application domain extension have been specifically developed to store and exchange energy simulation results [68].
} 
tics defined by typologies or by the users, using monthly quasi-steady-state simple energy models. Some GIS-based simulations include electrical devices and domestic hot water energy calculations but effects of the urban environment and the occupant behaviors are generally neglected or coarsely considered. Results are sometimes validated with measured annual aggregated energy consumption. Hence, these models represent an alternative to classical bottom-up approaches in order to calculate the annual energy demand, with the advantage of considering explicitly, but roughly, each urban building. Nonetheless, they are not able to consider accurately the dynamics of the building energy demand. To overcome this limitation and calculate hourly energy demand for each building rather than only monthly demand, Tian et al. [70] applied an EnergyPlus model to each building extracted from GIS. Using a computing cluster to parallelize the different simulations, only 4 hours of simulation were necessary to simulate about 10,000 buildings over a year. Nonetheless, given that each model is independent from the others, no interaction is considered. A similar method was used by Reinhart et al. [71] on a lower scale.

\subsection{Summary and discussion}

Simulating the energy demand of each building of an urban area at a district or city scale requires to explicitly model each building; this is microsimulation. In such an approach, it is essential to consider the impact of the urban environment on the energy needs of the simulated buildings. As shown in Figure 2, different types of models referring to different scales may be used to estimate building energy demand in an urban context.

More precisely, Figure 3 positions the different urban energy models with 
respect to their domain size and temporal resolution, i.e. the shortest time step which could be considered. Some of the above-mentioned studies are also plotted on the graph with respect to their spatial resolution, i.e. the level of detail for the calculation of the incident radiations modified by the urban environment, and simulated period. As Figure 3 shows:

- UBEMs are designed to account in detail for the effects of urban surroundings on building energy needs. They also calculate surface temperature field. UBESs are mainly performed on restricted domains because the objective is to determine precisely the thermal behavior (high resolution) of a building in its urban environment (small domain). Furthermore, the simulation is generally too computationally expensive to simulate numerous buildings;

- Top-down and "implicit" bottom-up approaches are efficient for determining annual or, at least, monthly total building energy demand (or consumption) of a city (large domain), but it is impossible to access to the power demand of a particular building in the city (low resolution) as all buildings are not explicitly modeled on contrary to micro-simulations (UBES and CES);

- CEMs aim simulating the energy demand (notably GIS-based models), and sometimes the power demand, of numerous buildings while relatively simply considering effects of the urban context. Due to simplifications and lower resolution the computational cost of CESs are reduced compared to UBESs. But validity of simulation results at short time step is expected to be further analysed and confirmed. 
Hence, because of computational limitations, detailed models are used for small domain sizes and short periods, i.e. at building scale during a few days or weeks. Larger domains need simpler models, which generally imply lower spatial and / or temporal resolution in order to neglect some transient phenomena. As can be seen in Figure 3, developing simulations able to calculate the power demand (at least, hourly energy demand) at the district of city scale is complex as this requires using high resolution models on large domains. This objective may be achieved by:

(1) increasing computational capacities and / or use efficient numerical techniques and computational strategies (in particular optimized algorithms or parallelization);

(2) implementing computationally efficient modeling techniques and simplifications, which minimally impact on the accuracy of the urban energy model. This implies handling the induced uncertainties by performing sensitivity analyses.

In order to identify the main modeling techniques which are, or could be, used for city energy micro-simulation, and which ones appear the most suited for this purpose, next section gives an overview of the main models used in BES, UBES and CES potentially usable in micro-simulation.

\section{Overview of sub-models used in building and urban energy sim- ulations}

As introduced in Sec. 1.3, urban environment affects the energy needs of urban buildings by conditioning their boundary conditions in terms of shortwave and longwave radiations, airflows and local air temperature. There- 
fore, estimating external loads of urban buildings requires specific models (currently referred as sub-models) and couplings to assess microclimatic conditions as well as their effects on the building energy behavior especially through the envelope. In addition, towards detailed and integrated microsimulation of urban energy, diversity in behavior of occupants and equipments use at city scale should also be modeled using stochastic models and agents-based models $[12,53,63,72-74]$, Nonetheless, as BESs generally involve deterministic scenarios and this review focuses on physical models, these models are not further detailed.

Hence, the following gives an overview of the different existing methods used to estimate radiative exchanges and microclimatic conditions in urban areas as well as heat transfers through building envelopes.

\subsection{Radiations models}

\subsubsection{Solar radiations}

Alterations (shadowing and reflections) of solar (shortwave) radiations are identified as one of the loads which affect the most needs of urban buildings compared to stand-alone ones, in particular for low-energy building designed to maximize solar gains in winter [75].

Solar radiations are generally split into two categories: direct and diffuse radiations. Direct radiation comes directly from the sun, following its direction. It is generally provided in meteorological weather input data of BES. In urban environment, an important part of solar rays may be obstructed. This part can be estimated thanks to ray-tracing $[17,19,46]$ or to projections methods $[48,56,76]$ at each simulation time-step, or can be calculated for some days and regressed for the others to save computational time. Diffuse 
radiation corresponds to solar radiation diffused by the atmosphere. Diffuse flux can be provided by weather data or estimated using isotropic or anisotropic sky models [77]. Although BESs often assume diffuse radiation as isotropic and direclty derive it from weather input data, this simplification lead to substantial deviation in the estimated annual solar irradiance compared to more detailed anisotropic sky models [55], which, on the other hand, need more detailed parameterization. In addition, in urban areas, diffuse radiation is also often obstructed by surrounding constructions. The effective diffuse flux received by urban surfaces (assumed isotropic) is thus generally estimated based on the sky view factor of surfaces. This factor can be estimated by ray-tracing or projection methods as for direct radiation, but it is time-invariant on contrary to the shading factor of direct radiations.

In addition to shadowing, urban environments reflect solar radiations. It is generally accepted that urban environment reflects solar radiations isotropically following the Lambertian law. This assumption is acceptable for opaque materials and enables the radiosity method or simplified associated methods to be used $[56,61]$. The radiosity method is based on an analytic formulation of the problem on a finite number of surfaces, which leads to a matrix problem whose size depends on the model spatial resolution. In theory, infinite reflections should be considered when resolving this matrix problem by inversion, but in practice, the matrix problem is often solved iteratively, i.e. considering only a finite number of reflections.

\subsubsection{Longwave radiations}

Longwave radiations impacts on building energy needs are smaller than solar radiations effects [21], but urban infrared exchanges may still have 
substantial effects $[18,50]$.

Calculations of longwave radiations exchanges are similar to procedures used for diffuse solar radiations (radiosity and ray-tracing methods), excepted that transfers occur between both urban surfaces and with the sky. Nonetheless, it is often considered that urban materials are black-bodies [46, 58], because their emissivity is generally close to 1 , so that reflections are not considered. Moreover, longwave radiations emitted by urban surfaces depend on their respective temperatures. This coupling implies to iterate the thermal model and the radiative model until convergence, which can be very time consuming. Therefore, surrounding surface temperatures are often roughly estimated as equal to the air temperature [41], to the temperatures given by the radiative model without any converging iteration [21], or to the temperature estimated the previous time-step [53].

\subsubsection{Summary and discussion}

Radiosity and ray tracing methods are generally used to compute radiative transfers in urban areas. Simulation are computationally expensive because of the numerous calculations needed to estimate the incoming radiations for each surface considering the interactions with all the others. Computational time can be saved by reducing the number of surfaces considered (approximated formulation or decrease of the resolution) or to a reduction of the number of reflections considered. ${ }^{2}$ As simplifications can substantially alter the accuracy of predictions, sensitivity studies should be performed to

\footnotetext{
${ }^{2}$ It is also possible to accelerate ray tracing computations by using parallelization on graphics processing units (GPU).
} 
determine the best compromise between results accuracy and computational time and so the best level of modeling.

\subsection{Urban climate models}

It was observed for a long time that cities alter local climate. Indeed, temperature, wind features and species concentrations (such as humidity) are modified compared to rural areas, which impacts on the building energy needs (see Section 1.3). However, the modeling of urban microclimates is very complex because of cities' geometric complexity and heterogeneity as well as the wide range of spatial and temporal scales characterizing atmospheric phenomena [78]. In addition, governing equation of fluid dynamics are nonlinear and strong interactions between buildings and microclimate require the use of coupled approaches. Therefore, different modeling strategies were developed in UBES or CES to model urban microclimatic conditions and the induced boundary conditions. They are reviewed hereafter.

\subsubsection{Urban canopy models}

During the last decades, meteorologists developed models of urban areas to determine their impacts on mesoscale processes (see Ref. [79] for more information about urban boundary layer modeling and Ref. [80] for a complete review of such models). Such models are called urban canopy model (UCM). While first models simply parameterized urban surfaces using equivalent albedo, roughness, and others surface parameters [81], more recent models consider homogeneous cities with simple geometry. These simple geometries are generally 1D [82] or 2D [83] array of parallelepiped buildings, or street canyons [84]). Rasheed et al. [85] proposed a method to find an 
equivalent geometry of UCM, which fits as best as possible for real geometry of the city.

Urban canopy models estimate energy exchanges between horizontal and vertical surfaces of the representative urban element and the atmosphere, and representative values of air temperature and wind speed within the urban canopy are deduced. The thermal behavior of buildings is generally modeled with basic BEM.

\subsubsection{Microclimatic models}

To estimate temperature and wind distribution within the urban canopy layer in detail, CFD should generally be used, as done in Ref. [86] for CES and in Ref. $[18,21]$ for (U)BES. However, these studies stressed the high computational cost of CFD, while the microclimatic model has theoretically to be coupled with BEM using an iterative process to determine accurately surface temperatures.

Otherwise, to enlarge the domain and energy demand simulation from a single urban building during some days to a neighborhood during several months, fluid dynamic modeling can be simplified by applying energy balance to large control volumes, which corresponds to a zonal approach [15, 61]. This method, coupled with the empirical-based wind field model QUIC-URB [60], is used by Gros et al. [58, 59] to simulate the microclimate in EnviBatE (Figure 3). Although the generalization of such models is not assured because of the empirical law describing some phenomena, such an approach requires less input parameters than CFD, and involves significantly less computational cost.

Another promising alternative to usual CFD simulations based on the 
Navier-Stokes equations as it does not alter model accuracy is to use the lattice Boltzmann method (LBM) for urban aeraulic simulation [87]. Due to its local and explicit formulation, this method is inherently parallel and allows a very cost effective implementation on GPUs [88] thus substantially reducing computational time compared to usual CFD methods.

\subsubsection{Measured and generated weather data}

Local measured data can also be specified as inputs for the urban building energy model $[25,27]$. However, collecting suited measurements necessitate expensive and extensive experimental field campaigns, which are necessarily spatially and temporally limited, and which could only be set to existing place. To overcome this limitation, it is possible to extend measured weather data from one place (e.g. synoptic meteorological station usually located in airports) to another places thanks to extrapolation techniques or to weather generators $[36,37]$. These approaches do not necessitate additional calculations (only pre-process) and provide similar forms of input data as usual BES input data. However, they are not able to predict the effects of UHIcountermeasures on urban microclimate, except if the weather generation is launched again, with modified properties.

\subsubsection{Summary and discussion}

Ideally, CEMs have to be coupled with microclimate models, themselves coupled with a mesoclimate model, as suggested in Ref. [89]. But, to the best knowledge of the authors, this has still not been achieved because of computational and methodological limitations.

Nowadays, climatologists couple mesoscale models with urban canopy 
models, which replace in a simple way microclimate and city energy models. By contrast, urban energy engineers couple their micro-simulations of city with urban climate models, but generally with many simplifications. Nevertheless, because of the complexity and computational costs of such coupled approaches compared to the expected accuracy improvement, CES often neglect microclimate (the white crosses in Figure 3 indicate the references that model microclimate). Indeed, SUNtool developers evaluated the determination of velocity, temperature and pressure fields via CFD as "not computationally tractable", and explained that error induced by simplified models are "similar or larger than errors due to ignoring urban-rural temperature differences" [54]. However, since then and as shown in Table 2, semi-empirical models have been improved and CFD have become more accessible for urban simulation thanks to increase in computational capacities and the development of efficient computational approaches such as the LBM, which makes microclimatic models more suitable for use in CES.

To conclude, on both sides (urban climatology and urban energy engineering), models become more and more sophisticated thanks to the continual improvements of computer capacities, and it is probable that, in the future, urban canopy models would be urban energy micro-simulation with real explicit representation of the city. But, for the moment, detailed simulation tools were mostly used for simple geometrical cases or relatively small urban areas. Reciprocally, simplified models were applied on more complex configurations and large urban areas. 


\subsection{Envelope models}

Being the interface between indoors and outdoors, which mainly conditions heating and cooling energy needs, the envelop modeling is critical for micro-simulation. This part presents the main envelope models used in (U)BES and CES. Soil models are not developed in this paper, but the models used are quite similar to envelope models.

\subsubsection{Resistance-Capacitance analogy method}

The most common envelope model is based on electrical analogy obtained by discretization of the wall in layers (usually one, two or three) characterized by specific thermal resistance and capacitance (R-C) [18, 53, 72, 74, 90, 91]. The determination of the $\mathrm{R}-\mathrm{C}$ values can be law-driven (white-box), or datadriven (grey-box). ${ }^{3}$ In the first case, value are deduced from a discrete form of the heat equation, according to material properties. In the second case, training stages are necessary in order to determine optimal values. This method is easy to implement, and to adapt to any type of wall, but the choice of the width of the layer - and so the thermal capacitance - is not generic as it depends on the thermal depth penetration, which itself depends on the solicitation frequency [93]. Indeed, Berthou [94] showed that the optimal R-C values which match measurements have to be modified every month for a better accuracy.

Usual R-C methods are well suited for calculation of energy demand over a long period because rapid thermal dynamics become negligible. However, these models become too inaccurate when considering short dynamics, as

\footnotetext{
${ }^{3}$ It also exists black-box models [92] using regressions not based on physical model
} 
required to assess power demand. To increase the accuracy, it is possible to increase the number of layers (i.e. finite difference method, as in [16]), but this also increases the computational cost.

\subsubsection{Spatially-analytical method}

Because the accuracy of discrete numerical methods (as finite difference) is limited by the number of layers considered, especially at the boundaries, Wang et al. [95] proposed a spatially-analytical scheme for building envelope in urban canopy model. This approach accurately reproduced the thermal behavior of the walls (without discontinuity, allowing considering thin layers), was unconditionally stable and computationally efficient. Nonetheless, applying analytic methods to heterogeneous (multilayered) envelopes adds continuity equations and thus increases computational cost. Furthermore, the analytic formulation is composed of an infinite series of terms, and even if these terms tend to zero, their truncation order depends on the fabric considered.

\subsubsection{Response factors method \\ In Gros et al.'s building model [58] the conductive heat transfer is com- puted using the response factor method, an external representation method similar to the coefficient transfer function method used in EnergyPlus default method [41] and TRNSYS [44]. These external representation methods di- rectly express the conductive heat fluxes at the inside and outside wall faces as a linear function of the historical values of surfaces temperatures. Their time series values are obtained by discrete convolution of the external loads}


(heat flux or temperature) and the pre-calculated weighted factors. These factors, pre-calculated with usual analytical or numerical methods, correspond to the time series values of the wall surface temperatures exposed to unitary external loads. Thus, on contrary to implicit finite discretisation methods, the response factors method, after pre-calculation, avoids considering all internal nodes temperature and to inverse a matrix problem. This is particularly interesting when considering high discretization of the wall to improve the model accuracy (especially when numerous internal nodes are considered). Nonetheless, the shorter the time step is, the higher the number of factors is.

\subsubsection{Reduction methods}

The objective of the reduction methods is to characterize as accurately as possible a detailed model with a minimal number of parameters. These parameters are determined with mathematical methods by diagonalizing the matrix problem in a specific base.

For example, a second order reduction model called Grey-box [96] was used in SUNtool [54]. This model estimated energy need of a building with two parameters (one for the static and the second for the transient behavior) via transfer functions. These parameters are defined according to the typology of the building. However, this method is only valid for the cases from which the transfer functions have been beforehand defined, and the physical meaning of these parameters is lost.

Alternatively, Kim et al. [97] proposed a reduced model for an urban building envelope. In this case, a reduction technique was applied to the thermal model of the building envelope. With this technique, only 7 equa- 
tions were required to characterize accurately the thermal dynamics of the buildings, instead of the 194 initial equations. Compared to the detailed model, the computational cost of the reduced model was strongly decreased without compromising accuracy. Hence, reduction method allows to consider high level of wall discretization and hence to estimate accurately the conductive heat flux while using low computational resources.

\subsubsection{Summary and discussion}

Simple R-C models are often used to simulate the thermal behavior of envelopes, mainly because they are relatively cost effective compared to detailed models. However, such approaches only give rough estimations of the dynamics of building energy demand. On the other hand, other approaches as weighted factor or reduction methods enable building envelope to be considered with a high level of detail without leading to prohibitive calculation time. Therefore, these methods appear promising for urban energy simulations.

The drawback of these last methods is that the model parameterization is assumed constant during the whole simulated period. This assumption can be strong, in particular for natural ventilation which is very variable and can strongly affects the building energy need. In order to consider these changes, it is necessary to compute again the external representation or reduced models. These additional steps increase computational cost and reduce the interest of such approaches. Alternatives may be found in non-linear systems methods. 


\section{Conclusions and outlooks}

Many approaches to simulate city energy demand exist, but only microsimulation is adapted to calculate individually the power demand of all buildings within an urban area. To the best knowledge of the authors, there is still no entirely validated tool able to simulate accurately and explicitly the power demand of urban buildings at the city scale, which can be explained, at least partly, by the substantial computational cost required.

Indeed, urban energy micro-simulations rely on a high level of detail for large domains. As a consequence, simulations are computationally expensive, especially when they include microclimatic modeling. In order to reduce computational costs, physical and model simplifications and computationally efficient urban environmental and climatic approaches are needed. With respect to simplification, some models were developed, but studies are still to be carried out to assess the level of simplification suited for use in urban energy micro-simulation and to validate them, especially at short time-step. With respect to computationally efficient approaches, problem formulation and numerical technics suited for massive parallelization will certainly play an important role in the decrease of the computational costs.

Nonetheless, although simplifications required by urban scale energy microsimulation may increase results uncertainties to some extent, it is worth mentioning that the uncertainty of input parameters may induce larger uncertainties than uncertainties involved by model simplifications. Therefore, their determination is also a crucial issue for urban energy micro-simulation, and their uncertainties have to be integrated during the modeling process. 


\section{Acknowledgments}

The authors want to thank EDF (Electricity of France) R\&D for its financial, scientific, and technical support.

\section{References}

[1] UN, Department of Population; Division Economic and Social Affairs. World urbanization prospects: the 2014 revision, 2014.

[2] IEA, International Energy Agency, IEA - Statistics (2013). URL http://www.iea.org/statistics/

[3] IEA, International Energy Agency. World Energy Outlook 2014 (2014).

[4] IPCC, Fourth Assessment Report: Climate Change (2007).

[5] E. Bozonnet, R. Belarbi, F. Allard, Thermal Behaviour of buildings: modelling the impact of urban heat island, Journal of Harbin Institute of Technology 14 (Sup.) (2007) 19-22.

[6] J. Keirstead, M. Jennings, A. Sivakumar, A review of urban energy system models: Approaches, challenges and opportunities, Renewable and Sustainable Energy Reviews 16 (6) (2012) 3847-3866.

[7] EU, European Parliament. Directive 2010/31/EU on energy performance of buildings (May 2010).

[8] Eurostat, Database - Eurostat (2014).

URL http://ec.europa.eu/eurostat/web/energy/data/database 
[9] D. Perez, A framework to model and simulate the disaggregated energy flows supplying buildings in urban areas, Ph.D. thesis, École polytechnique fédérale de Lausanne (2014).

[10] D. J. Bourgeois, Detailed occupancy prediction, occupancy-sensing control and advanced behavioural modelling within whole-building energy simulation, Ph.D. thesis, Université Laval Québec (2005).

[11] Y. Shimoda, T. Asahi, A. Taniguchi, M. Mizuno, Evaluation of city-scale impact of residential energy conservation measures using the detailed end-use simulation model, Energy 32 (9) (2007) 1617-1633.

[12] J. Page, Simulating occupant presence and behaviour in buildings, Ph.D. thesis, Ecole polytechnique fédérale de Lausanne (2007).

[13] D. Yan, W. O’Brien, T. Hong, X. Feng, H. Burak Gunay, F. Tahmasebi, A. Mahdavi, Occupant behavior modeling for building performance simulation: Current state and future challenges, Energy and Buildings 107 (2015) 264-278.

[14] A. Grandjean, J. Adnot, G. Binet, A review and an analysis of the residential electric load curve models, Renewable and Sustainable Energy Reviews 16 (9) (2012) 6539-6565.

[15] F. S. de la Flor, S. A. Dominguez, Modelling microclimate in urban environments and assessing its influence on the performance of surrounding buildings, Energy and Buildings 36 (5) (2004) 403-413.

[16] J. He, A. Hoyano, T. Asawa, A numerical simulation tool for predicting 
the impact of outdoor thermal environment on building energy performance, Applied Energy 86 (9) (2009) 1596-1605.

[17] J. Strømann-Andersen, P. Sattrup, The urban canyon and building energy use: Urban density versus daylight and passive solar gains, Energy and Buildings 43 (8) (2011) 2011-2020.

[18] J. Bouyer, C. Inard, M. Musy, Microclimatic coupling as a solution to improve building energy simulation in an urban context, Energy and Buildings 43 (7) (2011) 1549-1559.

[19] D. Kesten, A. Tereci, A. Strzalka, U. Eicker, A method to quantify the energy performance in urban quarters, HVAC\&R Research 18 (1-2) (2012) 100-111.

[20] J. Allegrini, V. Dorer, J. Carmeliet, Influence of the urban microclimate in street canyons on the energy demand for space cooling and heating of buildings, Energy and Buildings 55 (2012) 823-832.

[21] X. Yang, L. Zhao, M. Bruse, Q. Meng, An integrated simulation method for building energy performance assessment in urban environments, Energy and Buildings 54 (2012) 243-251.

[22] H. Kawai, T. Asawa, R. Saito, R. Sato, Numerical study: How does a high-rise building affect the surrounding thermal environment by its shading?, in: 30th International PLEA Conference, CEPT University, Ahmedabad, 2014.

[23] R. Stupka, C. Kennedy, Impact of neighborhood density on building 
energy demand and potential supply via the urban metabolism, ACEE Summer Study on Energy Efficiency in Buildings (2010) 239-252.

[24] L. Merlier, On the interactions between urban structures and air flows: A numerical study of the effects of urban morphology on the building wind environment and the related building energy loads, Ph.D. thesis, INSA de Lyon (2015).

[25] M. Santamouris, N. Papanikolaou, I. Livada, I. Koronakis, C. Georgakis, A. Argiriou, D. N. Assimakopoulos, On the impact of urban climate on the energy consumption of buildings, Solar energy 70 (3) (2001) 201-216.

[26] M. Kolokotroni, Y. Zhang, R. Watkins, The London Heat Island and building cooling design, Solar Energy 81 (1) (2007) 102-110.

[27] M. Assimakopoulos, G. Mihalakakou, H. Flocas, Simulating the thermal behaviour of a building during summer period in the urban environment, Renewable Energy 32 (11) (2007) 1805-1816.

[28] F. Ali-Toudert, Energy efficiency of urban buildings: significance of urban geometry, building construction and climate conditions, in: The seventh International Conference on Urban Climate. Yokohama, Japan, Vol. 29, 2009.

[29] T. R. Oke, The energetic basis of the urban heat island, Quarterly Journal of the Royal Meteorological Society 108 (455) (1982) 1-24.

[30] L. G. Swan, V. I. Ugursal, Modeling of end-use energy consumption in the residential sector: A review of modeling techniques, Renewable and Sustainable Energy Reviews 13 (8) (2009) 1819-1835. 
[31] W. Tian, R. Choudhary, A probabilistic energy model for non-domestic building sectors applied to analysis of school buildings in greater London, Energy and Buildings 54 (2012) 1-11.

[32] M. Kavgic, A. Mavrogianni, D. Mumovic, A. Summerfield, Z. Stevanovic, M. Djurovic-Petrovic, A review of bottom-up building stock models for energy consumption in the residential sector, Building and Environment 45 (7) (2010) 1683-1697.

[33] C. F. Reinhart, C. Cerezo Davila, Urban building energy modeling - A review of a nascent field, Building and Environment 97 (2016) 196-202.

[34] S. Heiple, D. J. Sailor, Using building energy simulation and geospatial modeling techniques to determine high resolution building sector energy consumption profiles, Energy and Buildings 40 (8) (2008) 1426-1436.

[35] P. Caputo, G. Costa, S. Ferrari, A supporting method for defining energy strategies in the building sector at urban scale, Energy Policy 55 (2013) 261-270.

[36] S. Oxizidis, A. Dudek, A. Papadopoulos, A computational method to assess the impact of urban climate on buildings using modeled climatic data, Energy and Buildings 40 (3) (2008) 215-223.

[37] M. Kolokotroni, X. Ren, M. Davies, A. Mavrogianni, London's urban heat island: Impact on current and future energy consumption in office buildings, Energy and Buildings 47 (2012) 302-311.

[38] Y. Kikegawa, Y. Genchi, H. Kondo, K. Hanaki, Impacts of cityblock-scale countermeasures against urban heat-island phenomena upon 
a building's energy-consumption for air-conditioning, Applied Energy 83 (6) (2006) 649-668.

[39] T. Ihara, Y. Kikegawa, K. Asahi, Y. Genchi, H. Kondo, Changes in year-round air temperature and annual energy consumption in office building areas by urban heat-island countermeasures and energy-saving measures, Applied Energy 85 (1) (2008) 12-25.

[40] F. Salamanca, A. Krpo, A. Martilli, A. Clappier, A new building energy model coupled with an urban canopy parameterization for urban climate simulations - part I. formulation, verification, and sensitivity analysis of the model, Theoretical and Applied Climatology 99 (3-4) (2010) 331344 .

[41] U.S. Departement of Energy, EnergyPlus Energy Simulation Software (2015).

URL http://apps1.eere.energy.gov/buildings/energyplus/index.cfm

[42] ENVI-MET GmbH, ENVI-met website (2015).

URL http://www.envi-met.com/

[43] J. Allegrini, V. Dorer, J. Carmeliet, Analysis of convective heat transfer at building façades in street canyons and its influence on the predictions of space cooling demand in buildings, Journal of Wind Engineering and Industrial Aerodynamics 104-106 (2012) 464-473.

[44] Thermal Energy System Specialists, LLC, TRNSYS Transient System Simulation Tool (2015).

URL http://www.trnsys.com/ 
[45] J. Huber, C. Nytsch-Geusen, Development of modeling and simulation strategies for large-scale urban districts, in: Proceedings of Building Simulation, 2011, pp. 1753-1760.

[46] T. Asawa, A. Hoyano, K. Nakaohkubo, Thermal design tool for outdoor spaces based on heat balance simulation using a 3d-CAD system, Building and Environment 43 (12) (2008) 2112-2123.

[47] ANSYS, FLUENT 6.3 User's Guide (2015).

URL http://aerojet.engr.ucdavis.edu/fluenthelp/html/ug/main_pre. htm

[48] F. Miguet, D. Groleau, A daylight simulation tool for urban and architectural spaces - application to transmitted direct and diffuse light through glazing, Building and Environment 37 (2002) 833-843.

[49] F. Archambeau, N. Méchitoua, M. Sakiz, Code Saturne: A Finite Volume Code for the computation of turbulent incompressible flows - Industrial Applications, International Journal on Finite Volumes (2004).

[50] L. Malys, M. Musy, C. Inard, Microclimate and building energy consumption: study of different coupling methods, Advances in Building Energy Research (2015) 1-24

[51] M. Musy, L. Malys, others, The use of SOLENE-microclimat to assess adaptation strategies at the district scale, in: IC2UHI, 2014.

[52] A. Hénon, P. G. Mestayer, D. Groleau, J. Voogt, High resolution thermoradiative modeling of an urban fragment in Marseilles city center dur- 
ing the UBL-ESCOMPTE campaign, Building and Environment 46 (9) (2011) 1747-1764.

[53] D. Robinson, F. Haldi, J. Kämpf, P. Leroux, D. Perez, A. Rasheed, U. Wilke, CitySim: Comprehensive micro-simulation of resource flows for sustainable urban planning, in: Eleventh International IBPSA Conference, 2009, pp. 1083-1090.

[54] D. Robinson, N. Campbell, W. Gaiser, K. Kabel, A. Le-Mouel, N. Morel, J. Page, S. Stankovic, A. Stone, SUNtool - A new modelling paradigm for simulating and optimising urban sustainability, Solar Energy 81 (9) (2007) 1196-1211.

[55] D. Robinson, A. Stone, Solar radiation modelling in the urban context, Solar Energy 77 (3) (2004) 295-309.

[56] D. Robinson, A. Stone, A simplified radiosity algorithm for general urban radiation exchange, Building Services Engineering Research and Technology 26 (4) (2005) 271-284.

[57] K. Orehounig, G. Mavromatidis, R. Evins, V. Dorer, J. Carmeliet, Predicting energy consumption of a neighborhood using building performance simulations, Building Simulation and Optimization (BSO 2014), UCL, London, UK.

[58] A. Gros, E. Bozonnet, C. Inard, Cool materials impact at district scale - Coupling building energy and microclimate models, Sustainable Cities and Society 13 (2014) 254-266. 
[59] A. Gros, E. Bozonnet, C. Inard, M. Musy, Simulation tools to assess microclimate and building energy - A case study on the design of a new district, Energy and Buildings (2015)

[60] E. R. Pardyjak, M. J. Brown, QUIC URB v. 1.1. Theory and Users Guide (2003).

[61] E. Bozonnet, R. Belarbi, F. Allard, Modelling solar effects on the heat and mass transfer in a street canyon, a simplified approach, Solar Energy 79 (1) (2005) 10-24.

[62] R. Kaden, Thomas H. Kolbe, City-wide total energy demand estimation of buildings using semantic $3 \mathrm{~d}$ city models ans statistical data, in: ISPRS Annals of the Photogrammetry, Remote Sensing and Spatial Information Sciences, Vol. 2, 2013, p. W1.

[63] J.-M. Bahu, A. Koch, A. Kremers, S. Murshed, Towards a 3d spatial urban energy modelling approach, in: ISPRS Annals of Photogrammetry, Remote Sensing and Spatial Information Sciences, Vol. 1, Istanbul, Turkey, 2013, pp. 33-41.

[64] R. Nouvel, K.-H. Brassel, M. Bruse, E. Duminil, V. Coors, U. Eicker, D. Robinson, SimStadt, a new workflow-driven urban energy simulation platform for CityGML city models, in: Proceedings of International Conference CISBAT 2015 Future Buildings and Districts Sustainability from Nano to Urban Scale, LESO-PB, EPFL, 2015, pp. 889-894.

[65] R. Nouvel, A. Mastrucci, U. Leopold, O. Baume, V. Coors, U. Eicker, Combining GIS-based statistical and engineering urban heatconsump- 
tion models: Towards a new framework for multi-scalepolicy support, Energy and Buildings 107 (2015) 204-212.

[66] G. Agugiaro, Energy planning tools and CityGML-based 3d virtual city models: experiences from Trento (Italy), Appl Geomat, 2015.

[67] Q. Li, S. Jige Quan, G. Augenbroe, P. Pei-Ju Yang, J. Brown, Building Energy Modelling at Urban Scale: Integration of Reduced Order energy Model with Geographical Information, in: 14th International Conference of IBPSA, Hyderabad, India, 2015.

[68] R. Nouvel, J.-M. Bahu, R. Kaden, J. Kämpf, P. Cipriano, M. Lauster, K.-H. Haefele, E. Munoz, O. Tournaire, E. Casper, Development of the Citygml Application Domain Extension Energy for Urban Energy Simulation, in: 14th International Conference of IBPSA, Hyderabad, India, 2015.

[69] C. Ratti, N. Baker, K. Steemers, Energy consumption and urban texture, Energy and Buildings 37 (7) (2005) 762-776.

[70] W. Tian, A. Rysanek, R. Choudhary, Y. Heo, High Resolution Energy Simulations at City Scale, in: 14th International Conference of IBPSA, Hyderabad, India, 2015, pp. 239-246.

[71] C. Reinhart, T. Dogan, J. A. Jakubiec, T. Rakha, A. Sang, Umi-an urban simulation environment for building energy use, daylighting and walkability, in: 13th Conference of International Building Performance Simulation Association, Chambery, France, 2013. 
[72] T. Berthou, B. Duplessis, P. Rivière, P. Stabat, D. Casetta, D. Marchio, Smart-E: A Tool for Energy Demand Simulation and Optimization at the City Scale, in: 14th International Conference of IBPSA, Hyderabad, India, 2015.

[73] P. Riederer, V. Partenay, N. Perez, C. Nocito, R. Trigance, T. Guiot, Development of A simulation Platform For The Evaluation Of District Energy System Performance, in: 14th International Conference of IBPSA, Hyderabad, India, 2015, pp. 2499-2506.

[74] R. Baetens, R. De Coninck, F. Jorissen, D. Picard, L. Helsen, D. Saelens, OPENIDEAS - An Open Framework for Integrated District Energy Simulations, in: 14th International Conference of IBPSA, Hyderabad, India, 2015.

[75] J. Bouyer, Modélisation et simulation des microclimats urbains: Etudes de l'impact de l'aménagement urbain sur les consommations énergétiques des bâtiments., Ph.D. thesis, University of Nantes (Sep. 2009).

[76] A. Yezioro, E. Shaviv, Shading: A Design Tool for Analyzing Mutual Shading Between Buildings, Solar Energy 52 (1) (1994) 27-37.

[77] A. Gros, E. Bozonnet, C. Inard, Modelling the radiative exchanges in urban areas: A review, Advances in Building Energy Research 5 (1) (2011) 163-206.

[78] B. Blocken, Computational Fluid Dynamics for urban physics: Importance, scales, possibilities, limitations and ten tips and tricks towards 
accurate and reliable simulations, Building and Environment 91 (2015) 219-245.

[79] J. F. Barlow, Progress in observing and modelling the urban boundary layer, Urban Climate 10 (2014) 216-240.

[80] A. Martilli, Current research and future challenges in urban mesoscale modelling, International Journal of Climatology 27 (14) (2007) 19091918.

[81] T. Fujino, T. Asaeda, C. Vu Thanh, Numerical analyses of urban thermal environment in a basin climate application of a k-epsilon model to complex terrain, Journal of Wind Engineering and Industrial Aerodynamics 81 (1999) 159-169.

[82] A. Martilli, A. Clappier, M. W. Rotach, An urban surface exchange parameterisation for mesoscale models, Boundary-Layer Meteorology 104 (2) (2002) 261-304.

[83] R. Ooka, T. Sato, K. Harayama, S. Murakami, Y. Kawamoto, Thermal Energy Balance Analysis of the Tokyo Metropolitan Area Using a Mesoscale Meteorological Model Incorporating an Urban Canopy Model, Boundary-Layer Meteorology 138 (1) (2011) 77-97.

[84] V. Masson, A physically-based scheme for the urban energy budget in atmospheric models, Boudary-Layer Meteorology 94 (2000) 357-397.

[85] A. Rasheed, D. Robinson, A. Clappier, C. Narayanan, D. Lakehal, Representing complex urban geometries in mesoscale modeling, International Journal of Climatology 31 (2) (2011) 289-301. 
[86] M. Heidarinejad, N. W. Mattise, M. Dahlhausen, S. K. Nikkho, J. Liu, S. Gracik, K. Liu, K. Sharma, H. Zhang, J. R. Wentz, M. S. Roudsari, G. Pitchurov, J. Srebic, Urban Scale Modeling of Campus Building Using Virtual PULSE, in: 14th International Conference of IBPSA, Hyderabad, India, 2015.

[87] C. Obrecht, F. Kuznik, L. Merlier, J.-J. Roux, B. Tourancheau, Towards aeraulic simulations at urban scale using the lattice Boltzmann method, Environmental Fluid Mechanics 15 (2014) 753-770.

[88] F. Kuznik, C. Obrecht, G. Rusaouen, J.-J. Roux, LBM based flow simulation using GPU computing processor, Computers and Mathematics with Applications 59 (7) (2010) 2380-2392.

[89] V. Dorer, J. Allegrini, K. Orehounig, P. Moonen, G. Upadhyay, J. Kämpf, J. Carmeliet, Modelling the urban microclimate and its impact on the energy demand of buildings and building clusters, Proceedings of BS, 2013.

[90] N. Perez, P. Riederer, C. Inard, V. Partenay, Thermal Building Modeling Adapted to District Energy Simulation, in: 14th International Conference of IBPSA, Hyderabad, India, 2015.

[91] J. Schiefelbein, M. Diekerhof, A. Javadi, G. Bode, R. Streblow, D. Müller, A. Monti, Development of a Tool Chain for Complex City District Energy System Modeling and Simulation, in: 14th International Conference of IBPSA, Hyderabad, India, 2015. 
[92] P. Béguery, P. Pflaum, N. Rousset, F. Bourry, A. Wantier, Simulation for the Evaluation of Energy Management Algorithms at the district Level - Example of Use Case from the AMBASSADOR Project, in: 14th International Conference of IBPSA, Hyderabad, India, 2015.

[93] J.-J. Roux, Proposition de modèles simplifiés pour l'étude du comportement thermique des bâtiments, Ph.D. thesis, INSA de Lyon (1984).

[94] T. Berthou, Développement de modèles de bâtiment pour la prévision de charge de climatisation et l'élaboration de stratégies d'optimisation énergétique et d'effacement, Ph.D. thesis, Ecole Nationale Supérieure des Mines de Paris (2013).

[95] Z.-H. Wang, E. Bou-Zeid, J. A. Smith, A Spatially-Analytical Scheme for Surface Temperatures and Conductive Heat Fluxes in Urban Canopy Models, Boundary-Layer Meteorology 138 (2) (2011) 171-193.

[96] F. Déqué, F. Ollivier, A. Poblador, Grey boxes used to represent buildings with a minimum number of geometric and thermal parameters, Energy and buildings 31 (1) (2000) 29-35.

[97] E.-J. Kim, G. Plessis, J.-L. Hubert, J.-J. Roux, Urban energy simulation: Simplification and reduction of building envelope models, Energy and Buildings 84 (2014) 193-202.

[98] P. A. Mirzaei, F. Haghighat, Approaches to study Urban Heat Island - Abilities and limitations, Building and Environment 45 (10) (2010) 2192-2201. 


\section{List of Tables}

1 Brief presentation of some CES . . . . . . . . . . . . 47

2 General characteristics of urban climate models. . . . . . . . 48 


\begin{tabular}{|l|l|}
\hline Name \& Reference & Short presentation \\
\hline Smart-E [72] & $\begin{array}{l}\text { Simulation environment for study on the potentiality of flexibility in the building thermal and electrical } \\
\text { demand, focusing on power demand. }\end{array}$ \\
\hline DIMOSIM [73] & $\begin{array}{l}\text { Simulation platform for optimization of the global district energy system included energy system, ther- } \\
\text { mal network, energy production and storage; implemented in Matlab }\end{array}$ \\
\hline $\begin{array}{l}\text { Virtual PULSE } \\
{[86]}\end{array}$ & $\begin{array}{l}\text { Web-based urban scale modeling platform for quantitative assessments of the influence of urban neigh- } \\
\text { borhoods on building energy consumption (building energy and air flow). }\end{array}$ \\
\hline $\begin{array}{l}\text { AMBASSADOR } \\
\text { Project [92] }\end{array}$ & $\begin{array}{l}\text { Simulation platform for grid management optimization for energy at building and city scale, based on } \\
\text { Matlab Simulink environment. }\end{array}$ \\
\hline OpenIDEAS [74] & $\begin{array}{l}\text { Open framework for integrated district energy simulations including simultaneous transient simulation of } \\
\text { thermal, control and electric systems at building and neighborhood level, building models and stochastic } \\
\text { model of occupant behaviors; based on Modelica libraries and Python scripts. }\end{array}$ \\
\hline M91]'s tool chain & $\begin{array}{l}\text { Tool chain for complex city district modeling and simulation from GIS and database, developed with } \\
\text { Modelica and Python interfaces }\end{array}$ \\
\hline
\end{tabular}

Table 1: Brief presentation of some CES 


\begin{tabular}{|c|c|c|c|c|c|c|}
\hline Method & Results & Main application & $\begin{array}{l}\text { Maximum domain } \\
\text { size }\end{array}$ & Spatial resolution & $\begin{array}{l}\text { Temporal } \\
\text { resolution }\end{array}$ & $\begin{array}{l}\text { Computational } \\
\text { cost }\end{array}$ \\
\hline $\begin{array}{l}\text { Urban } \\
\text { models* }\end{array}$ & $\begin{array}{l}\text { Global and aver- } \\
\text { aged temperature } \\
\text { and wind at city } \\
\text { scale }\end{array}$ & Urban climate & City & $1-10 \mathrm{~m}$ & Hour & Medium \\
\hline $\begin{array}{l}\text { Microclimate } \\
\text { (Micro-scale } \\
\text { CFD* + thermo- } \\
\text { radiative model) }\end{array}$ & $\begin{array}{l}\text { High resolution } \\
\text { fields of temper- } \\
\text { atures and wind } \\
\text { velocity }\end{array}$ & $\begin{array}{l}\text { Urban microcli- } \\
\text { mate, pedestrian } \\
\text { comfort }\end{array}$ & District & $0.1-10 \mathrm{~m}$ & Second & $\begin{array}{lrr}\text { Very high } & \text { for } \\
\text { LES (lower } & \text { with } \\
\text { LBM-LES), } & \text { high } \\
\text { for RANS } & \\
\end{array}$ \\
\hline $\begin{array}{l}\text { Zonal and empiri- } \\
\text { cal models }\end{array}$ & $\begin{array}{l}\text { Low resolution } \\
\text { fields of temper- } \\
\text { atures and wind } \\
\text { velocity }\end{array}$ & $\begin{array}{lr}\text { Urban } & \text { microcli- } \\
\text { mate, } & \text { building } \\
\text { energy } & \text { simulation }\end{array}$ & City & $1-10 \mathrm{~m}$ & Hour & Medium \\
\hline $\begin{array}{l}\text { Weather genera- } \\
\text { tor }\end{array}$ & $\begin{array}{l}\text { Global or local in- } \\
\text { formation }\end{array}$ & $\begin{array}{ll}\text { Urban } & \text { (micro)- } \\
\text { climate, } & \text { building } \\
\text { energy simulation }\end{array}$ & City & $0.1 \mathrm{~m}-1 \mathrm{~km}$ & Hour & $\begin{array}{l}\text { Preprocessed (Very } \\
\text { high if climate } \\
\text { model; Low if } \\
\text { regression) }\end{array}$ \\
\hline $\begin{array}{l}\text { Full-scale mea- } \\
\text { surements }\end{array}$ & Local information & $\begin{array}{lr}\text { Local } & \text { climate, } \\
\text { building } & \text { energy } \\
\text { simulation } & \\
\end{array}$ & City & $1 \mathrm{~m}-1 \mathrm{~km}$ & Second & - \\
\hline
\end{tabular}

* See Table 1 in [98] for more details

Table 2: General characteristics of urban climate models. 


\section{List of Figures}

1 Modification of the energy balance of an urban building compared to a stand-alone one . . . . . . . . . . . 50

2 Scales of the different categories of simulation. . . . . . . . 51

3 Comparison of the domains of availability of the different categories of energy simulation of urban buildings. . . . . . . 52

4 Nesting of the urban climate scales and related modeling approaches. . . . . . . . . . . . . . . 5 53 


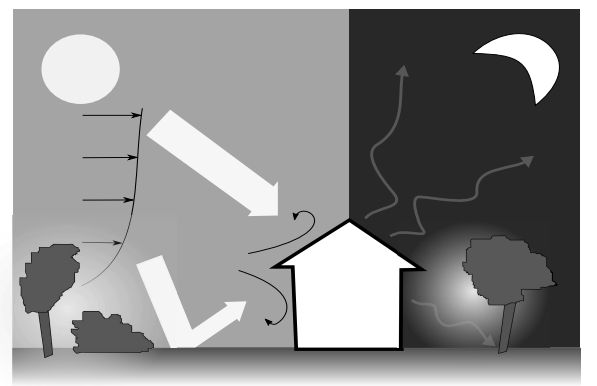

(a) Stand-alone building

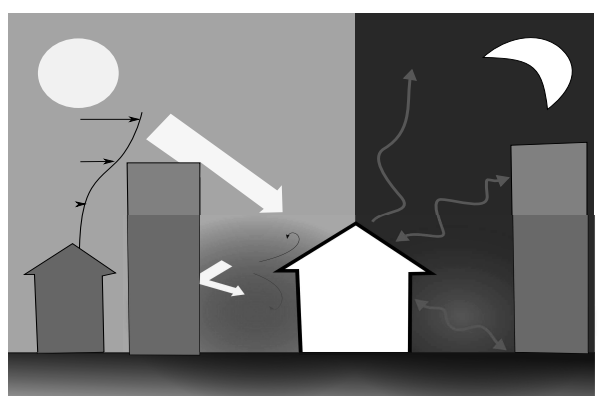

(b) Urban building

Figure 1: Modification of the energy balance of an urban building compared to a standalone one 


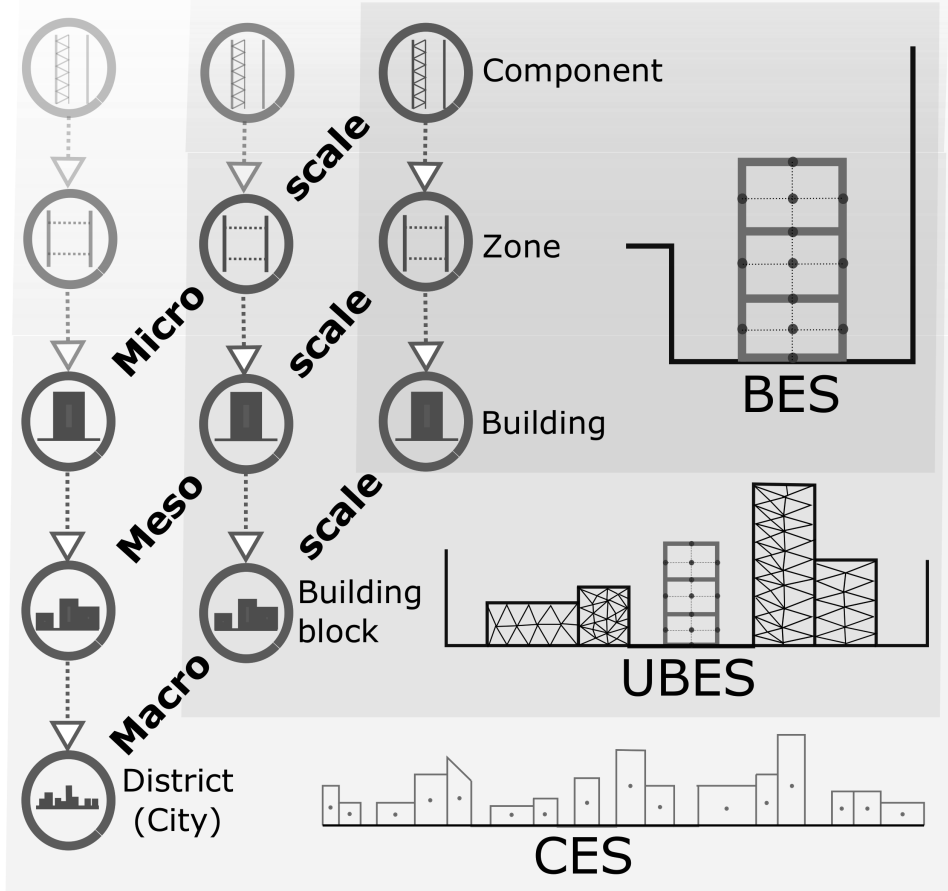

Figure 2: Scales of the different categories of simulation. 


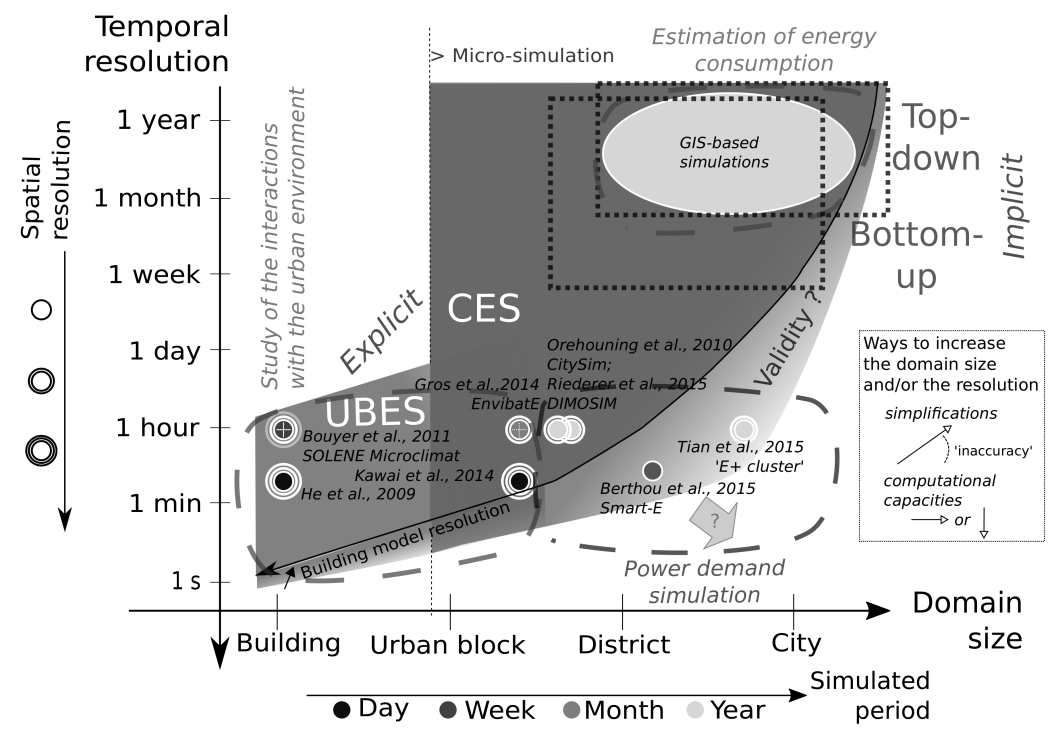

Figure 3: Comparison of the domains of availability of the different categories of energy simulation of urban buildings. 


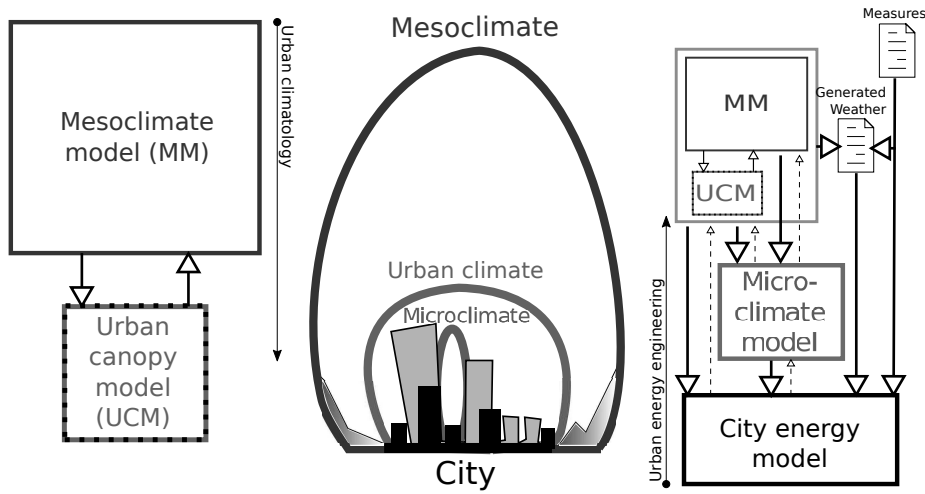

Figure 4: Nesting of the urban climate scales and related modeling approaches. 